\title{
Морфология межслоевой поверхности и микро-рамановские спектры в слоистых пленках топологических изоляторов на основе теллурида висмута
}

\author{
(С) Л.Н. Лукьянова ${ }^{1}$, А.Ю. Бибик ${ }^{2}$, В.А. Асеев ${ }^{2}$, О.А. Усов ${ }^{1}$, И.В. Макаренко ${ }^{1}$, \\ В.Н. Петров ${ }^{1}$, Н.В. Никоноров ${ }^{2}$ \\ ${ }^{1}$ Физико-технический институт им. А.Ф. Иоффре Российской академии наук, \\ 194021 Санкт-Петербург, Россия \\ ${ }^{2}$ Национальный исследовательский университет \\ информационных технологий, механики и оптики, \\ 197101 Санкт-Петербург, Россия \\ E-mail: lidia.lukyanova@mail.ioffe.ru
}

(Получена 12 декабря 2016 г. Принята к печати 19 декабря 2016 г.)

В тонких слоистых пленках $n-\mathrm{Bi}_{2} \mathrm{Te}_{3}$ и твердых растворов на основе $\mathrm{Bi}_{2} \mathrm{Te}_{3}$ исследованы резонансные микро-рамановские спектры и морфология межслоевой ван-дер-ваальсовой поверхности. Установлено влияние состава, толщины, морфологии поверхности и метода получения пленок на относительную интенсивность рамановских фононов, чувствительных к поверхностным топологическим состояниям фермионов Дирака.

DOI: 10.21883/FTP.2017.06.44553.13

\section{1. Введение}

Свойства поверхностных состояний дираковских фермионов в наноструктурированных пленках на основе теллурида висмута, относящихся к классу топологических изоляторов, в настоящее время широко исследуются методом микро-рамановской спектроскопии [1-4]. Слоистые пленки $n$-типа проводимости $\mathrm{Bi}_{2} \mathrm{Te}_{3}$ и твердых растворов $\mathrm{Bi}_{2} \mathrm{Te}_{3-y} \mathrm{Se}_{y}, \mathrm{Bi}_{2-x} \mathrm{Sb}_{x} \mathrm{Te}_{3-y} \mathrm{Se}_{y}$ относятся к классу трехмерных топологических изоляторов, в которых благодаря сильному спин-орбитальному взаимодействию электронов в объеме формируется топологический изолятор, а поверхность обладает аномальными металлическими свойствами с высокой подвижностью носителей заряда и линейной дисперсией, характерной для дираковских фермионов [5,6]. Анализ отношений интенсивностей активных и неактивных фононных мод и данных, характеризующих морфологию межслоевой поверхности, позволяет оценить влияние топологических поверхностных состояний дираковских фермионов на интенсивность неактивных мод в слоистых пленках различного состава и разной толщины, приготовленных различными методами.

Кристаллическая структура пленок на основе теллурида висмута состоит из плоских анизотропных слоев, в каждом из которых находятся пять атомных плоскостей, образующих квинтеты, разделенные ван-дер-ваальсовыми щелями. Атомные слои Те и $\mathrm{Bi}$ в квинтете чередуются в последовательности $\left(-\mathrm{Te}^{(1)}-\mathrm{Bi}-\mathrm{Te}^{(2)}-\mathrm{Bi}-\mathrm{Te}^{(1)}-\right)$. В твердых растворах атомы $\mathrm{Sb}$ занимают места $\mathrm{Bi}$, атомы $\mathrm{Se}-$ места $\mathrm{Te}^{(2)}$ или $\mathrm{Te}^{(1)}$. Такая структура обеспечивает легкое расслоение кристаллов по границам квинтетов вдоль плоскости (0001), перпендикулярной оси с.

\section{2. Спектры рамановского рассеяния и морфологии межслоевой поверхности}

Измерения резонансных спектров рамановского рассеяния проводились при комнатной температуре на установке Renishaw micro-Raman spectrometer RM 2000. На рис. 1-3 приведены рамановские спектры высокочастотных активных, $E_{g}^{2}, A_{1 g}^{2}$, и неактивных, $A_{1 u}^{2}$, фононов для пленок $n-\mathrm{Bi}_{2} \mathrm{Te}_{3}, n-\mathrm{Bi}_{2} \mathrm{Te}_{3-y} \mathrm{Se}_{y}$ и $n-\mathrm{Bi}_{2-x} \mathrm{Sb}_{x} \mathrm{Te}_{3-y} \mathrm{Se}_{y}$. Появление в рамановских спектрах неактивных фононов $A_{1 u}^{2}$ с уменьшением толщины образцов связано с нарушением инверсионной симметрии кристалла в поверхностном слое и используется для оценки электронных поверхностных состояний дираковских фермионов [1-4].

Слоистые пленки (рис. 1-3) были получены механическим расщеплением монокристаллических зерен, которые были вырезаны из объемных слитков, выращенных методом направленной кристаллизации с прецизионной регулировкой температуры на фронте кристаллизации (образцы 1, 4, 5) и без дополнительной регулировки температуры (образец 3). Образец 2 получен механическим расщеплением монокристаллических слитков, выращенных методом Чохральского. В обозначениях кривых на рис. 1-3 первая цифра соответствует типу образца.

Исследование морфологии межслоевой поверхности (0001) слоистых монокристаллических пленок халькогенидов висмута и сурьмы проводилось полуконтактным методом атомно-силовой микроскопии (ACM) на приборе Р47. Рельеф межслоевой поверхности (0001), образующейся при разрыве связей между атомами $\mathrm{Te}^{(1)}-\mathrm{Te}^{(1)}$ в слоях термоэлектриков, имеет вид террас, ступеней и островков, формирующихся в процессе роста за счет диффузии и упругого взаимодействия дислока- 


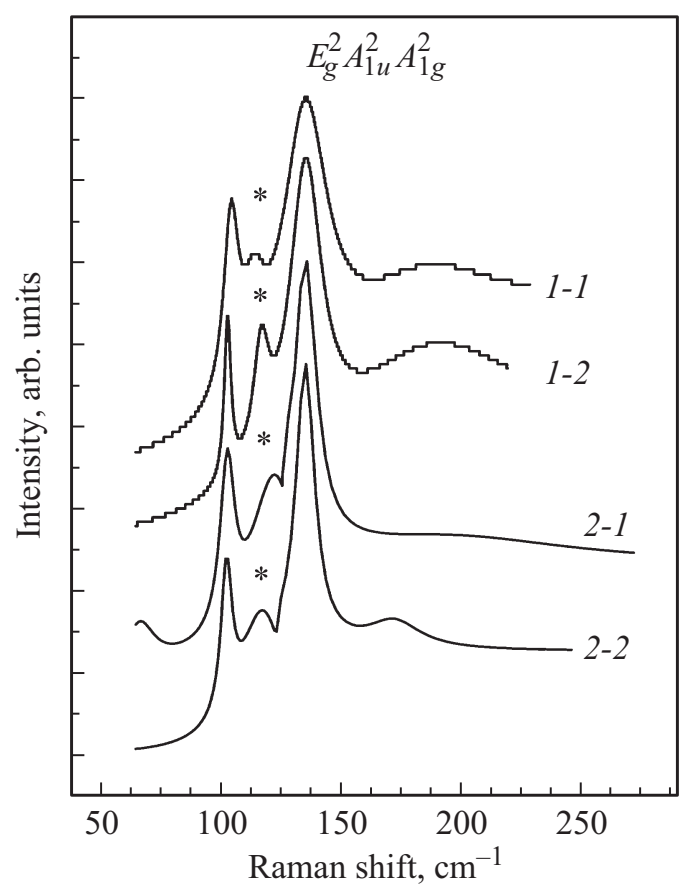

Рис. 1. Рамановские спектры слоев $n-\mathrm{Bi}_{2} \mathrm{Te}_{3}(1-1,1-2)$ и твердого раствора $n-\mathrm{Bi}_{2} \mathrm{Te}_{2.88} \mathrm{Se}_{0.12}(2-1,2-2)$. Коэффициент термоэдс $\alpha=-270(1-1,1-2),-285$ мкВ $\cdot \mathrm{K}^{-1}(2-1,2-2)$; толщина пленки $d=220(1-1), 120$ (1-2), 220 (2-1), 120 нм (2-2).

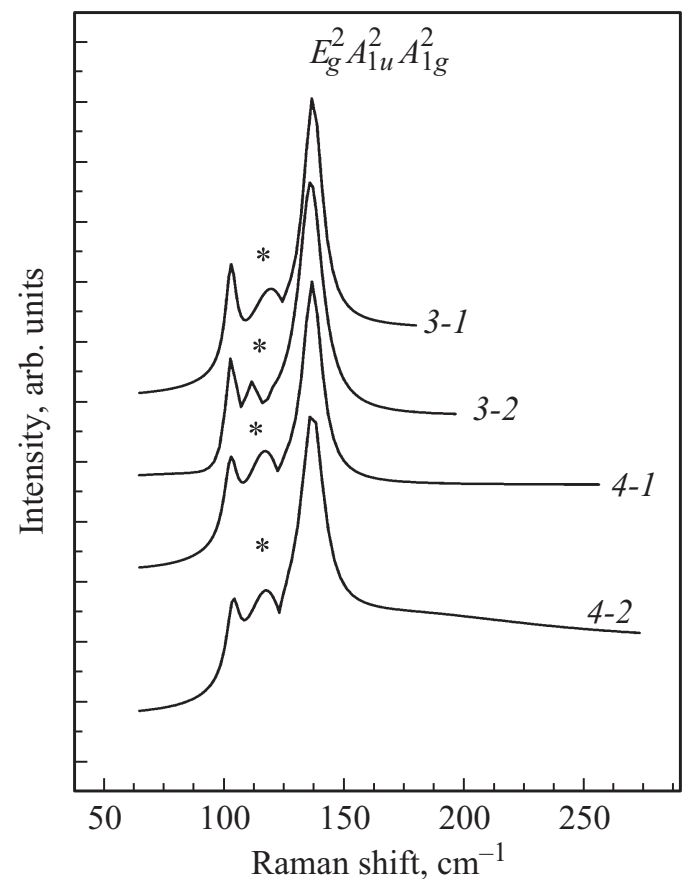

Рис. 2. Рамановские спектры тонких слоев твердого раствора $n-\mathrm{Bi}_{2} \mathrm{Te}_{2.7} \mathrm{Se}_{0.3}$. Коэффициент термоэдс $\alpha=-305$ (3-1, 3-2), $-315 \mathrm{M \kappa B} \cdot \mathrm{K}^{-1}(4-1,4-2)$; толщина пленки $d=350$ (3-1), 300 (3-2), 280 (4-1), 150 нм (4-2).

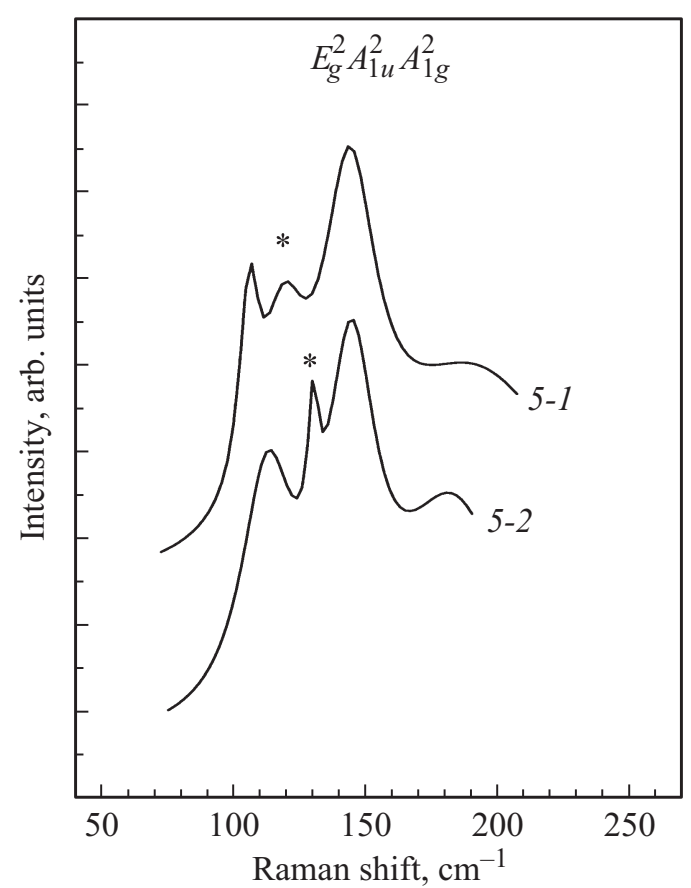

Рис. 3. Рамановские спектры тонких слоев твердого раствора $n$ - $\mathrm{Bi}_{1.6} \mathrm{Sb}_{0.4} \mathrm{Te}_{2.91} \mathrm{Se}_{0.09}$. Коэффициент термоэдс $\alpha=-280 \mathrm{M \kappa B} \cdot \mathrm{K}^{-1}$, толщина пленки $d=200 \quad(5-1)$, 120 нм (5-2).

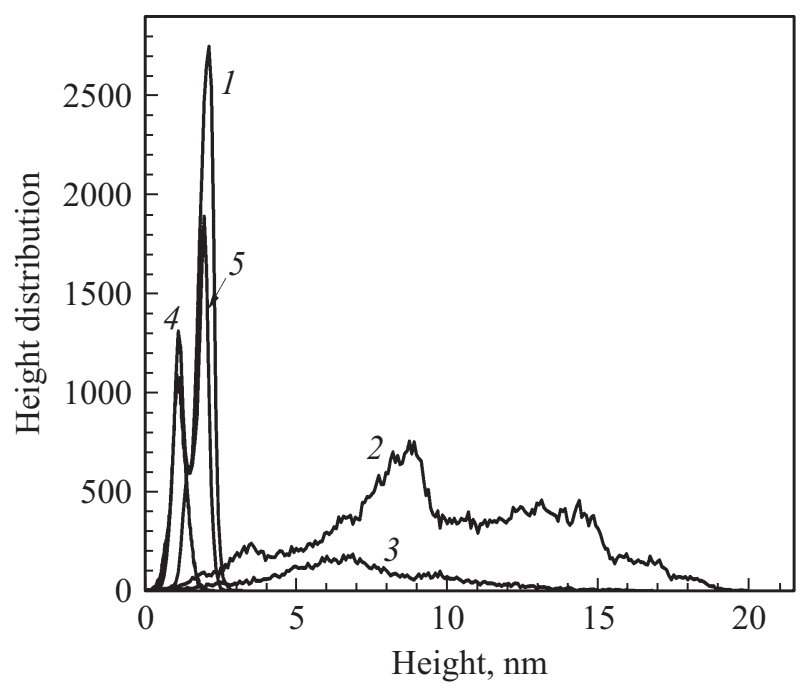

Рис. 4. Распределение нанофрагментов на межслоевой поверхности (0001) в зависимости от их высоты: $1-n-\mathrm{Bi}_{2} \mathrm{Te}_{3}$

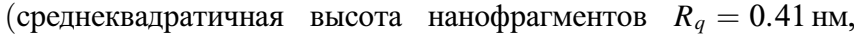
средняя высота функции распределения $\left.H_{a}=2.05 \mathrm{Hм}\right) ; 2-$ $n-\mathrm{Bi}_{2} \mathrm{Te}_{2.88} \mathrm{Se}_{0.12}\left(R_{q}=3.8 \mathrm{HM}, H_{a}=8 \mathrm{HM}\right) ; 3-n-\mathrm{Bi}_{2} \mathrm{Te}_{2.7} \mathrm{Se}_{0.3}$ $\left(R_{q}=0.65 \mathrm{HM}, H_{a}=6.7 \mathrm{HM}\right) ; 4-n-\mathrm{Bi}_{2} \mathrm{Te}_{2.7} \mathrm{Se}_{0.3}\left(R_{q}=0.26 \mathrm{HM}\right.$, $\left.H_{a}=1.05 \mathrm{HM}\right) ; \quad 5-n-\mathrm{Bi}_{1.6} \mathrm{Sb}_{0.4} \mathrm{Te}_{2.91} \mathrm{Se}_{0.09} \quad\left(R_{q}=0.3 \mathrm{HM}\right.$, $\left.H_{a}=1.9 \mathrm{HM}\right)$. 


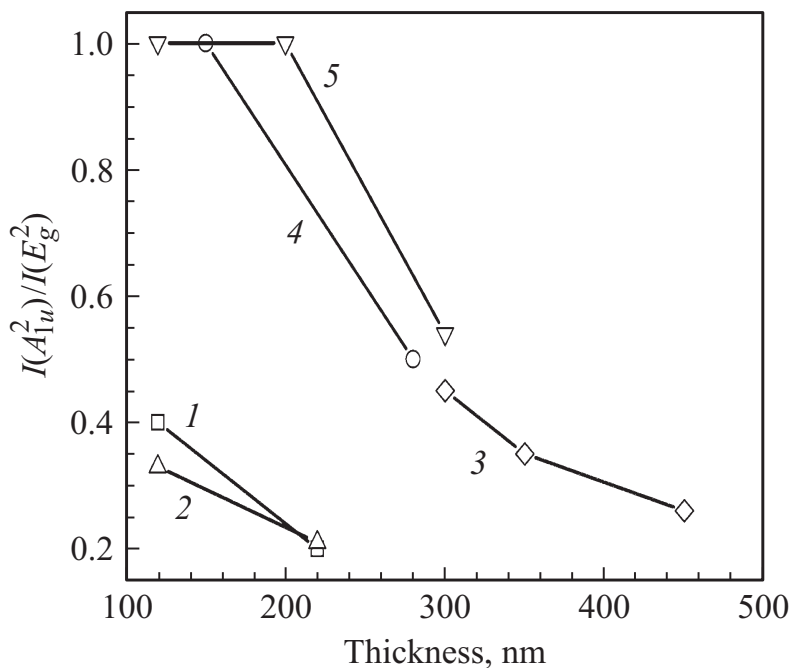

Рис. 5. Относительные интенсивности фононных мод $I\left(A_{1 u}^{2}\right) /$ $I\left(E_{g}^{2}\right)$ от толщины слоев в $n-\mathrm{Bi}_{2} \mathrm{Te}_{3}(1), n-\mathrm{Bi}_{2} \mathrm{Te}_{2.88} \mathrm{Se}_{0.12}$ (2), $n-\mathrm{Bi}_{2} \mathrm{Te}_{2.7} \mathrm{Se}_{0.3}(3,4)$ и $n-\mathrm{Bi}_{1.6} \mathrm{Sb}_{0.4} \mathrm{Te}_{2.91} \mathrm{Se}_{0.09}$ (5).

ций, которые являются преобладающим видом дефектов в исследуемых термоэлектриках [3]. Рельеф поверхности характеризуется распределением нанофрагментов на межслоевой поверхности (0001) в зависимости от их высоты (рис. 4).

Поскольку интенсивности продольных мод $I\left(A_{1 u}^{2}\right)$ и $I\left(A_{g}^{2}\right)$ более чувствительны к влиянию электронфононного взаимодействия при резонансном рамановском рассеянии [1-3] по сравнению с поперечной модой $E_{g}^{2}$, то для анализа рамановских спектров, приведенных на рис. 2-4, были построены зависимости относительных интенсивностей фононных мод $I\left(A_{1 u}^{2}\right) / I\left(E_{g}^{2}\right)$ от толщины слоев (рис. 5). Относительные интенсивности $I\left(A_{1 u}^{2}\right) / I\left(E_{g}^{2}\right) \approx 1$ наблюдались в наиболее тонких слоях твердых растворов $n$ - $\mathrm{Bi}_{2} \mathrm{Te}_{2.7} \mathrm{Se}_{0.3}, n-\mathrm{Bi}_{1.6} \mathrm{Sb}_{0.4} \mathrm{Te}_{2.91} \mathrm{Se}_{0.9}$ при высоком качестве межслоевой поверхности (0001) с малыми величинами среднеквадратичной высоты фрагментов $R_{q}$ и средней высоты функции распределения $H_{a}$ (pис. 4,5$)$. В $n-\mathrm{Bi}_{2} \mathrm{Te}_{3}$ отношение $I\left(A_{1 u}^{2}\right) / I\left(E_{g}^{2}\right)$ значительно меньше, а средняя высота функции распределения нанофрагментов на межслоевой поверхности (0001) больше по сравнению с твердыми растворами. Технология получения образцов, состав и толщина влияют на величину относительной интенсивности $I\left(A_{1 u}^{2}\right) / I\left(E_{g}^{2}\right)$ и приводят к ее снижению в $n-\mathrm{Bi}_{2} \mathrm{Te}_{3}$, в составе $n-\mathrm{Bi}_{2} \mathrm{Te}_{2.88} \mathrm{Se}_{0.12}$, выращенном методом Чохральского, и в $n-\mathrm{Bi}_{2} \mathrm{Te}_{2.7} \mathrm{Se}_{0.3}$, полученном механическим расслоением термоэлектрика, выращенного без дополнительной регулировки температуры (рис. 4,5 ).

\section{3. Заключение}

Проведены исследования спектров рамановского рассеяния и морфологии поверхности методами АCM в теллуриде висмута и твердых растворах на его основе при замещениях атомов основного соединения в подрешетке висмута и в обеих подрешетках при различных значениях коэффициента термоэдс. Показано, что систематизация отношений интенсивностей высокочастотных рамановских фононов в трехмерных топологических изоляторах $n$-типа проводимости $\mathrm{Bi}_{2} \mathrm{Te}_{3}$ и твердых растворах на его основе в зависимости от толщины, морфологии поверхности и термоэдс образцов представляет интерес как независимый способ оценки влияния топологических поверхностных состояний дираковсих фермионов на транспортные и оптические свойства халькогенидов.

Финансовая поддержка исследований частично получена в рамках проекта РФФИ № 16-08-00478.

\section{Список литературы}

[1] K.M.F. Shahil, M.Z. Hossain, D. Teweldebrhan, A.A. Balandin. Appl. Phys. Let., 95, 153103 (2010).

[2] Yu.D. Glinka, S. Babakiray, T.A. Johnson, D. Lederman. J. Phys.: Condens. Matter, 27, 052203 (2015).

[3] Л.Н. Лукьянова, А.Ю. Бибик, В.А. Асеев, О.А. Усов, И.В. Макаренко, В.Н. Петров, Н.В. Никоноров, В.А. Кутасов. ФТТ, 58, 1390 (2016).

[4] K. Saha, K. Legare, I. Garate. Phys. Rev. Lett., 115, 176405 (2015).

[5] M.Z. Hasan, C.L. Kane. Rev. Mod. Phys., 82, 3045 (2010).

[6] D.-X. Qu, Y.S. Hor, J. Xiong, R.J. Cava, N.P. Ong. Science, 329, 821 (2010).

Редактор Л.В. Шаронова

\section{Morphology of the interlayer surface and micro-Raman spectra of layered films in bismuth telluride based topological insulators}

\author{
L.N. Lukyanova1 , A.Yu. Bibik', V.A. Aseev', O.A. Usov' ${ }^{1}$, \\ I.V. Makarenko ${ }^{1}$, V.N. Petrov ${ }^{1}$, N.V. Nikonorov ${ }^{2}$ \\ ${ }^{1}$ loffe Institute, \\ 194021 St. Petersburg, Russia, \\ ${ }^{2}$ Saint-Petersburg State University \\ of Informational Technologies, Mechanics and Optics, \\ 197101 St. Petersburg, Russia
}

Abstract Resonant micro-Raman spectra and interlayer van der Waals surface morphology are investigated for layered thin films of bismuth telluride and its solid solutions. It is shown how composition, thickness, surface morphology and the method of obtaining films effect on the relative intensity of the Raman active phonons that sensitive to topological surface states of Dirac fermions.

\section{Публикация материалов Конференции завериена.}

